\title{
STRATEGI PROMOSI BANYUWANGI SEBAGAI DESTINASI WISATA (STUDI KASUS PADA DINAS KEBUDAYAAN DAN PARIWISATA)
}

\author{
Chintiya Betari Avinda \\ I Nyoman Sudiarta \\ Ni Made Oka Karini \\ Email : betariavinda@gmail.com \\ PS. S1 Industri Perjalanan Wisata \\ Fakultas Pariwisata UNUD
}

\begin{abstract}
ABSTRAK
Kegiatan promosi yang efektif merupakan hal yang sangat esensial dalam pengembangan pariwisata di suatu daerah. Bauran promosi merupakan salah satu alat pemasaran, dapat digunakan untuk menginformasikan, membujuk dan mengingatkan calon wisatawan. Dalam kurun waktu 20112014 kunjungan wisatawan ke Banyuwangi mengalami peningkatan namun rata-rata lama tinggal wisatawan masih rendah. Penelitian dilakukan dengan tujuan untuk mengevaluasi strategi promosi yang telah dilakukan oleh Dinas Kebudayaan dan Pariwisata serta hambatan-hambatan yang dialami. Metode deskriptif kualitatif dilakukan dengan teknik pengumpulan data yang digunakan adalah dengan observasi, wawancara dengan kepala dinas dan staf dinas Kebudayaan dan Pariwisata Kabupaten Banyuwangi, serta studi kepustakaan. Hasil pengolahan data menunjukkan bahwa strategi promosi yang dilakukan oleh Dinas Kebudayaan dan Pariwisata Kabupaten Banyuwangi melalui bauran promosi sudah memberikan dampak positif terhadap kunjungan wisatawan namun belum cukup efektif untuk memeratakan kunjungan wisatawan dan meningkatkan lama tinggal wisatawan. Program-program advertising dan direct marketing yang dilakukan sudah efektif sedangkan sales promotion dan public relation belum cukup efektif. Dalam pelaksanaan strategi promosi juga terdapat faktor pendukung dan penghambat. Dari hasil pengolahan data disarankan kepada Dinas Kebudayaan dan Pariwisata untuk mengkaji ulang program bauran promosi yang kurang efektif, mengadakan pelatihan kepramuwisataan dan Bahasa Inggris, memperbanyak Tourist Information Center, serta menjalin kerjasama dengan stakeholder lainnya.
\end{abstract}

Kata kunci : Bauran Promosi, Strategi Promosi.

\section{LATAR BELAKANG}

Indonesia merupakan salah satu negara kepulauan terbesar di dunia dengan lima pulau besar yang dimiliki serta pulau-pulau kecil yang tersebar dari Sabang sampai Merauke. Perbedaan kondisi geografis serta tipologi masyarakat menjadikan Indonesia memiliki banyak kebudayaan, adat-istiadat, tradisi yang terangkum menjadi suatu suku bangsa yang beraneka ragam. Keanekaragaman yang dimiliki Indonesia tidak hanya menarik bagi wisatawan lokal, namun juga menjadi daya tarik yang kuat bagi wisatawan mancanegara. Perkembangan kepariwisataan di Indonesia tidak lepas dari adanya globalisasi dan perkembangan kepariwisataan di dunia. Adanya perubahan sosial dan ekonomi masyarakat dunia ikut memepengaruhi kegiatan pariwisata yang dulunya hanya bisa dilakukan oleh segelintir orang dengan kemampuan finansial yang diatas rata-rata. Perkembangan pariwisata di Indonesia dapat terlihat dari semakin banyaknya destinasi wisata yang muncul. Hal ini tidak lepas dari diberlakukannya Undang-undang No.22 Tahun 1999 tentang Pemerintahan Daerah yang memberikan kebebasan dan kewenangan kepada daerah untuk mengatur dan memanfaatkan sumber daya yang dimiliki dengan maksimal untuk menghasilkan pendapatan bagi daerah dan memperkanalkan potensi yang dimiliki oleh daerah. Adanya sistem Otonomi Daerah membuat beberapa daerah di Indonesia kini mulai 
mengoptimalkan potensi pariwisata yang dimilikinya dan salah satunya adalah Kabupaten Banyuwangi. Kabupaten Banyuwangi memiliki bentang alam yang beragam, mulai dari dataran tinggi berupa daerah pegunungan, dataran rendah serta garis pantai yang membentang sepanjang 175,8 km. Keberagaman yang dimiliki menjadikan Banyuwangi kaya akan potensi pariwisata. Pemerintah Kabupaten Banyuwangi mulai gencar memasarkan potensi wisata yang ada dengan melakukan promosi pariwisata. Promosi merupakan salah satu tahapan dalam pemasaran dimana tahap ini memiliki peran penting dalam usaha untuk meningkatkan kunjungan wisatawan. Kegiatan promosi yang efektif merupakan hal yang sangat esensial dalam pengembangan pariwisata di suatu daerah. Kebijakan pemerintah, staf pelayanan, kepuasan wisatawan adalah tiga faktor terpenting yang berpengaruh terhadap efektifitas promosi pariwisata (Vinh). Salah satu promosi adalah dengan membuat tagline "Sunrise of Java" dan "Diamond Triangle". Dalam kurun waktu lima tahun terakhir, pariwisata Banyuwangi mengalami perkembangan yang signifikan yang terlihat dari meningkatya jumlah kunjungan wisatawan ke Banyuwangi. Hal tersebut dapat dilihat dari jumlah kunjungan wisatawan pada 2013, wisatawan mancanegara mencapai 10.462 orang, meningkat 90 persen dibanding 2012 sebesar 5.502 orang. Adapun wisatawan nusantara meningkat 24 persen dari 860.831 orang pada tahun 2012 menjadi 1.057 .952 pada tahun 2013. Peningkatan kunjungan wisatawan yang cukup signifikan hanya terjadi di beberapa daya tarik wisata alam (Kawah Ijen, Pantai Plengkung, Pulau Merah, dan Pantai Watu Dodol) yang sudah terkenal di Banyuwangi.

Hal ini tentu tidak terlepas dari aktifitasaktifitas promosi yang dilakukan oleh Dinas Kebudayaan dan Pariwisata Kabupaten Banyuwangi, namun masih rendahnya tingkat lama tinggal wisatawan dan belum meratanya persebaran kunjungan wisatawan menjadi poin yang harus dievaluasi. Evaluasi strategi promosi melalui program bauran promosi yang dijalankan serta faktor pendukung dan faktor penghambat apa saja yang dialami dalam kegiatan promosi Banyuwangi sebagai destinasi wisata.

\section{METODE}

Penelitian menggunakan metode deskriptif kualitatif. Sugiyono (2005: 91) mengemukakan bahwa aktivitas analisis data kualitatif dilakukan secara interaktif dan berlangsung secara terus-menerus sampai tuntas, sehingga datanya sudah jenuh. Ruang lingkup data yang dicari adalah evaluasi strategi, bauran promosi (advertising, sales promotion, direct marketing, dan public relation), serta destinasi wisata.

\section{Jenis dan Sumber data}

Jenis data dibagi menjadi dua, yaitu data kualitatif yaitu data berupa kata-kata yang tertuang menjadi sebuah informasi dan bukan dalam bentuk angka serta yang didapatkan melalui observasi dan wawancara di lapangan serta data kuantitatif yaitu data yang berbentuk angka-angka atau bilangan yang diperoleh melalui studi kepustakaan. Sumber data dibagi menjadi dua, yaitu data primer berupa hasil wawancara yang dilakukan dengan informan dan data sekunder berupa informasi tambahan yang digunakan sebagai data pendukung data primer.

\section{Teknik pengumpulan data}

Data-data dikumpulkan dengan metode observasi partisipasi untuk memaksimalkan data yang akan diperoleh, in-dept interview semi terstruktur yang bersifat bebas dan fleksibel dibandingkan dengan wawancara terstruktur (Sugiyono 2012: 73-74) serta studi kepustakaan.

\section{Teknik penentuan informan}

Informan adalah orang yang dimanfaatkan untuk memberikan informasi tentang situasi dan kondisi latar penelitian, jadi ia harus mempunyai banyak pengalaman tentang latar penelitian dan harus sukarela menjadi anggota tim peelitian walaupun hanya bersifat informal. (Moleong, 2000:132). Informan yang dimanfaatkan untuk memberikan informasi ditetapkan menggunakan teknik purposive sampling, yang memiliki kriteria tersendiri yakni mengetahui dengan jelas dan memahami tentang hal-hal yang berkaitan dengan promosi Banyuwangi.

\section{Teknik analisis data}

Teknik analisis data yang digunakan adalah analisis deskriptif kualitatif. Teknik 
analisis ini mencakup tiga langkah, yaitu data reduction (reduksi data) yaitu merangkum, memilih hal-hal yang pokok, memfokuskan pada hal-hal yang penting, dicari tema dan polanya. Data display (penyajian data) yaitu data dirangkai menjadi kalimat yang tersusun secara sistematis dan logis. Conclusion drawing/verification (simpulan atau verifikasi) yaitu pengulangan dan penelusuran data kembali dengan tujuan untuk pemantapan simpulan yang didapat. (Sugiyono 2005: 91).

\section{HASIL}

Dinas Kebudayaan Dan Pariwisata Banyuwangi berlokasi di Jl. A. Yani 78 dibentuk berdasarkan Peraturan Bupati Banyuwangi Nomor 52 Tahun 2011 tentang Rincian Tugas, Fungsi dan Tata Kerja Dinas Kebudayaan dan Pariwisata Kabupaten Banyuwangi (Berita Daerah Kabupaten Banyuwangi Tahun 2011 Nomor 17/D). Memiliki visi "Mewujudkan Banyuwangi Sebagai Daerah Tujuan Wisata Nasional yang Berbasis Kebudayaan dan Potensi Alam Serta Lingkungan". Dijalankan oleh 40 orang staf yang terbagi ke dalam bidang kebudayaan, bidang pariwisata, dan bidang pemasaran. Dari aspek kuantitas, jumlah staf yang ada masih belum bisa mencukupi kapasitas untuk melaksanakan program dan menjalankan strategi yang sudah ditetapkan. Namun dari aspek kualitas, SDM yang dimiliki sudah mampu untuk menjalankan kegiatan kedinasan.

Untuk mewujudkan visi Banyuwangi sebagai daerah tujuan wisata, Dinas Kebudayaan dan Pariwisata memiiki sistem penatapan strategi yang disebut corporate strategy atau grand strategy dimana pembuat dan penyusun strategi adalah manajemen puncak. Strategi promosi terkonsep sentralisasi untuk mencapai tujuan Banyuwangi sebagai destinasi wisata nasional yang berbasis pada kearifan lokal. Pelaksanaan strategi promosi yang telah ditetapkan adalah dengan menggunakan bauran promosi (promotion mix) dan selanjutnya dievaluasi dengan menggunakan teori dari Kotler (Kotler (2005: 264) tentang unsur bauran promosi. Keempat bauran promosi (promotion mix) terdiri dari periklanan (advertising), promosi penjualan (sales promotion), pemasaran langsung (direct marketing), dan hubungan masyarakat (public relation). Terdapat faktor pendukung dan penghambat baik yang berasal dari dalam (faktor internal) maupun dari luar (faktor eksternal) yang mempengaruhi hasil dari program-program bauran promosi yang dijalankan.

\section{PEMBAHASAN \\ Evaluasi Program Bauran Promosi Advertising (Periklanan)}

Periklanan merupakan segala bentuk penyajian dan promosi ide, barang, atau jasa secara non-personal. Program- program periklanan (advertising) yang dijalankan oleh Dinas Kebudayaan dan Pariwisata Kabupaten Banyuwangi dengan menggunakan beberapa media, yaitu media cetak antara lain : inflight magazine Garuda Indonesia dan Lion Air yang melayani rute penerbangan dari Surabaya Banyuwangi - Surabaya (belum maksimal), memasang iklan di JTV (Jawa Pos Media Televisi) dan peluncuran aplikasi berbasis andorid "Banyuwangi Tourism" pada tanggal 11 April 2014 (belum efektif), serta pemanfaatan media luar dengan program pemasangan baliho, spanduk, poster dan billboard berisikan tentang jadwal-jadwal setiap event yang diselenggarakan sejak awal tahun hingga akhir tahun, serta lokasi event itu diselenggarakan di lokasi strategis (sudah baik dan maksimal).

Evaluasi Program Bauran Promosi Sales Promotion (Promosi Penjualan)

Promosi penjualan merupakan aktivitas promosi yang melibatkan semua aktivitas masyarakat untuk mempengaruhi hasrat konsumen potensial dan mencapai target penjualan. Promosi penjualan yang dilakukan akan membentuk suatu citra yang akan melekat terhadap suatu daerah. Dinas Kebudayaan dan Pariwisata melakukan promosi penjualan dengan melakukan branding melalui pembuatan tagline "The Sun Rise of Java" dan "I Love Banyuwangi " selain sebagai ajang promosi, pembuatan tagline juga berfungsi untuk meningkatkan rasa cinta terhadap daerah (efektif), mengikuti World EXPO MILAN ( WEM ) 2015 yang diselenggarakan di Milan tanggal 5-8 September dan Madrid Fitur 2016 yang diselenggarakan pada $17-25$ Januari di Spanyol serta menyelanggarakan pameran pameran budaya di ITB yang bekerjaama dengan IKAWANGI pada 19 September 2015 (efektif), membangun Taman Hiburan Rakyat 
di setiap kecamatan yang dilengkapi dengan fasilitas wi-fi (efektif).

Evaluasi Program Bauran Promosi Direct Marketing (Pemasaran Langsung)

Pemasaran langsung adalah pendekatan pemasaran yang berfungsi untuk mempertahankan pelanggan maupun meningkatkan kunjungan wisatawan dan memungkinkan adanya strategi sendiri untuk mendekatkan hubungan dengan konsumen secara langsung. Pemasaran langsung yang dilakukan oleh Dinas Kebudayaan dan Pariwisata Kabupaten Banyuwangi yaitu menyediakan TIC (Tourist Information Center) di area dinas sebagai media penyalur informasi yang menjangkau wisatawan secara langsung (efektif), pembuatan website yang dilengkapi dengan e-mail menyuguhkan tampilan yang menarik dan informatif serta selalu mengupdate berita-berita terbaru dan terkini mengenai Banyuwangi (efektif).

\section{Evaluasi Program Bauran Promosi Public Realations (Hubungan Masyarakat)}

Saluran promosi berupa hubungan masyarakat (public relations) adalah bentuk komunikasi non-personal yang bertujuan untuk menciptakan citra baik sebuah destinasi dan mengubah opini publik secara luas. Kegiatan hubungan masyarakat dilaksanakan oleh sekertariat dinas melalui program pelatihan Bahasa Inggris diikuti oleh 80 peserta yang berprofesi sebagai tukang ojek, supir angkot, tukang becak dan penambang belerang (belum efektif), mengadakan pelatihan kepramuwisataan di hotel Mahkota Plengkung yang bekerjasama dengan HPI cabang Banyuwangi pada tanggal 27-31 Mei 2013 (belum efektif), mengadakan sosialisasi kepada masyarakat bekerjasama dengan Kesehatan Kabupaten Banyuwangi dan Kepolisian Resor Banyuwangi dengan mengusung tema "Pemberdayaan Masyarakat Di Sekitar Objek Wisata" yang dilaksanakan pada 26-27 Maret 2013 dan menghidupkan kembali POKDARWIS (Kelompok Sadar Wisata) (belum efektif).

\section{Faktor Pendukung Strategi Promosi Banyuwangi Sebagai Destinasi Wisata}

Dalam promosi terdapat beberapa faktor yang mempengaruhi efektivitas dari kegiatan tersebut. Salah satu faktor yang mempengaruhi kegiatan promosi adalah faktor pendukung. Faktor pendukung adalah faktor-faktor yang menunjang keberhasilan promosi. Berikut ini adalah faktor-faktor pendukung promosi Banyuwangi sebagai destinasi wisata:

1. Keanekaragaman alam dan kekayaan seni budaya yang dimiliki Banyuwangi merupakan potensi yang besar untuk dapat dikembangkan dan dikelola menjadi sebuah daya tarik wisata.

2. Adanya dukungan dari Pemerintah Daerah terlihat dari banyaknya akses yang dibuka menuju Banyuwangi. Salah satunya adalah penyelesaian proyek pembangunan Bandar Udara Blimbingsari dan pembangunan marina untuk kapal pesiar.

3. Adanya kerjasama yang baik antar dinas yang berada dibawah SKPD (Satuan Kerja Pemerintah Daerah). Kerjasama tersebut tercermin dari diselenggarakannya rangkaian event tahunan oleh Dinas Kebudayaan dan Pariwisata yang juga bekerjasama dengan dinas lainnya seperti event Festival Batik, Festival Buah Lokal, dan Festival Sego Tempong yang bekerjasama dengan Dinas Perindustrian dan Perdagangan.

4. Perkembangan teknologi dan informasi memiliki pengaruh yang besar terhadap sebuah kegiatan pemasaran yang kemudian dimanfaatkan oleh Dinas Kebudayaan dan Pariwisata dengan meluncurkan aplikasi berbasis android serta peran aktif melalui penggunaan media sosial.

5. Pembangunan infrastruktur dengan meningkatkan fasilitas dan perbaikan infrastruktur secara merata di Kabupaten Banyuwangi terlebih akses-akses menuju kawasan Diamond Triangle (Segitiga Berlian) yaitu Kawah Ijen, Pantai Sukamade dan G-Land (Pantai Plengkung).

Faktor Penghambat Strategi Promosi Banyuwangi Sebagai Destinasi Wisata

Aktivitas promosi yang dijalankan oleh Dinas Kebudayaan dan Pariwisata Kabupaten Banyuwangi tidak selalu berjalan lancar, ada hambatan-hambatan yang mengurangi efektivitas kegiatan promosi. Hambatan tersebut antara lain:

1. Minimnya staf Dinas Kebudayaan dan Pariwisata Kabupaten Banyuwangi hanya dijalankan oleh 40 staf dengan rincian 30 
orang staf berstatus PNS dan 10 staf berstatus non-PNS.

2. Data-data mengenai daya tarik wisata alam, kekayaan budaya serta potensi lainnya belum tersedia secara akurat.

3. Minimnya anggaran dari pemerintah. Anggaran promosi yang ada masih kurang untuk bisa menciptakan promosi yang ideal.

4. Kurangnya keterlibatan masyarakat terhadap pembangunan pariwisata. Masyarakat cenderung konservatif dan menganut nilai-nilai tradisional yang secara tegas menolak adanya pengembangan pariwisata di daerahnya.

5. SDM yang ada di bidang pariwisata masih kurang yaitu hanya terdapat 27 orang pramuwisata dengan spesialisasi 25 orang pramuwisata yang ahli berbahasa Bahasa Inggris, 1 orang Bahasa Belanda, dan 1 orang Bahasa Jepang.

\section{SIMPULAN DAN SARAN Simpulan}

Strategi promosi dari Kabupaten Banyuwangi adalah corporate strategy dimana pembuat dan penyusun strategi adalah manajemen puncak yang dalam hal ini adalah Dinas Kebudayaan dan Pariwisata Kabupaten Banyuwangi. Pelaksanaan strategi promosi dilakukan dengan menggunakan bauran promosi (promotion mix) yang terdiri dari 4 saluran promosi yang dibaurkan. Dengan menggunakan periklanan, promosi penjualan, pemasaran langsung, dan hubungan masyarakat yang dibaurkan menjadi sebuah strategi promosi telah mampu meningkatkan kunjungan wisatawan ke Banyuwangi. Namun hal tersebut belum dibarengi dengan meratanya persebaran wisatawan ke daya tarik wisata yang sampai saat ini masih terfokus kepada daya tarik wisata alam.

Saran

Dengan memperhatikan temuan-temuan dalam penelitian, disampaikan saran-saran sebagai berikut :

1. Dinas Kebudayaan dan Pariwisata perlu melakukan pengkajian ulang terhadap program-program bauran promosi yang telah dan sedang berjalan dengan kurang efektif.
2. Mengadakan pelatihan-pelatihan terutama Bahasa Inggris, serta menyelenggarakan sosialisasi terkait kepariwisataan, kesehatan, dan pelestarian lingkungan kepada masyarakat umum.

3. Mengadakan pelatihan kepramuwisataan terhadap para pemandu wisata muda yang akan dapat menambah jumlah sumber daya manusia profesional dibidang pariwisata.

4. Menambah tourist information center di beberapa tempat potensial yang akan dikunjungi oleh banyak orang.

5. Menjalin kerjasama dengan stakeholder lainnya untuk meningkatkan kegiatan promosi Banyuwangi sebagai destinasi wisata.

6. Membuat produk wisata dengan menggabungkan potensi wisata budaya dengan alam, terutama potensi wisata yang belum banyak diketahui oleh masyarakat.

\section{DAFTAR PUSTAKA}

Kotler, Philip. 2005. Manajemen Pemasaran, Jilid 1 dan 2. Jakarta : PT. Indeks

Moleong, Lexy. J. 2000. Metodologi Penelitian Kualitatif. Bandung: PT Remaja Rosdakarya

Sugiyono. 2008. Metode Penelitian Pendidikan Pendekatan

Kuantitatif,vKualitatif, dan R\&D. Cetakan ke enam. Bandung: Alfabeta

Wen-Hsiang Lai, d. N. 2013.How Promotional Activities and Evaluative Factors Affect Destination Loyalty: Evidence From International Tourists of Vietnam. International Journal Of Marketing Studies,Vol. 5, No.1.

www.banyuwangitourism.com (diakses pada 18 Maret 2016)

www.banyuwangikab.go.id (diakses pada 18 Maret 2016). 
Jurnal IPTA

ISSN : 2338-8633

Vol. 4 No. 1, 2016 